\title{
Traumatic arteriovenous fistula supplied by the middle meningeal artery
}

\author{
Satoru Takeuchi • Yoshio Takasato
}

Received: 20 October 2010 / Accepted: 25 October 2010 /Published online: 5 November 2010

(C) Springer-Verlag 2010

We read with great interest the article entitled "Traumatic fistula between the middle meningeal artery and the sphenoparietal sinus" by Unterhofer et al. [3] in the Oct 2009 issue of Acta Neurochirurgica. The authors presented a case of post-traumatic fistula between the middle meningeal artery and the sphenoparietal sinus and discussed the relevant literature. They pointed out that the laterobasal fractures involving the floor of the middle temporal fosse can lead to fistula formation between the middle meningeal artery and the sphenoparietal sinus. Therefore, they stressed the need to include selective angiographic catheterization of the external carotid artery when bone damage after head injury involves the lateral skull base and a fistula is suspected on clinical grounds. We agree with the authors' opinion; however, we would like to comment on this issue. We previously reported a case of a traumatic middle meningeal arteriovenous fistula on the opposite side of a head injury [2].The patient hit the right side of their head. Computed tomography scans demonstrated a traumatic right temporal bone fracture, whereas

\footnotetext{
S. Takeuchi $(\bowtie)$

Department of Neurosurgery, National Defense Medical College, 3-2 Namiki,

Tokorozawa, Saitama 359-8513, Japan

e-mail: s.takeuchi@room.ocn.ne.jp

Y. Takasato

Department of Neurosurgery, National Hospital Organization

Disaster Medical Center,

Tokyo, Japan
}

there was no fracture on the left side. Cerebral angiograms 1 year after the head injury showed a dural arteriovenous fistula, which was fed by the left middle meningeal artery. Draining systems were mainly the middle meningeal vein and the sphenoparietal sinus. A review of the literature showed that there are some reported cases of traumatic middle meningeal arteriovenous fistula without skull fracture on the side of the lesion. Dura mater-bone separation [1] or distortion of the dura mater may cause the formation of a traumatic arteriovenous fistula fed by the middle meningeal artery without skull fracture. We suggest that a selective angiography of the external carotid artery should be performed in cases with clinical suspicions, even if there is no skull fracture.

Conflict of interest None.

\section{References}

1. Ford LE, McLaurin RL (1963) Mechanisms of extradural hematomas. J Neurosurg 20:760-769

2. Takeuchi S, Takasato Y, Masaoka H, Hayakawa T, Otani N, Yoshino Y, Yatsushige H, Sugawara T, Aoyagi C, Suzuki G (2009) A case of traumatic middle meningeal arteriovenous fistula on the side of the head opposite to the injured side. No Shinkei Geka 37:983-986

3. Unterhofer C, Chemelli A, Waldenberger P, Bauer R, Ortler M (2009) Traumatic fistula between the middle meningeal artery and the sphenoparietal sinus. Acta Neurochir (Wien) 151:13011304 